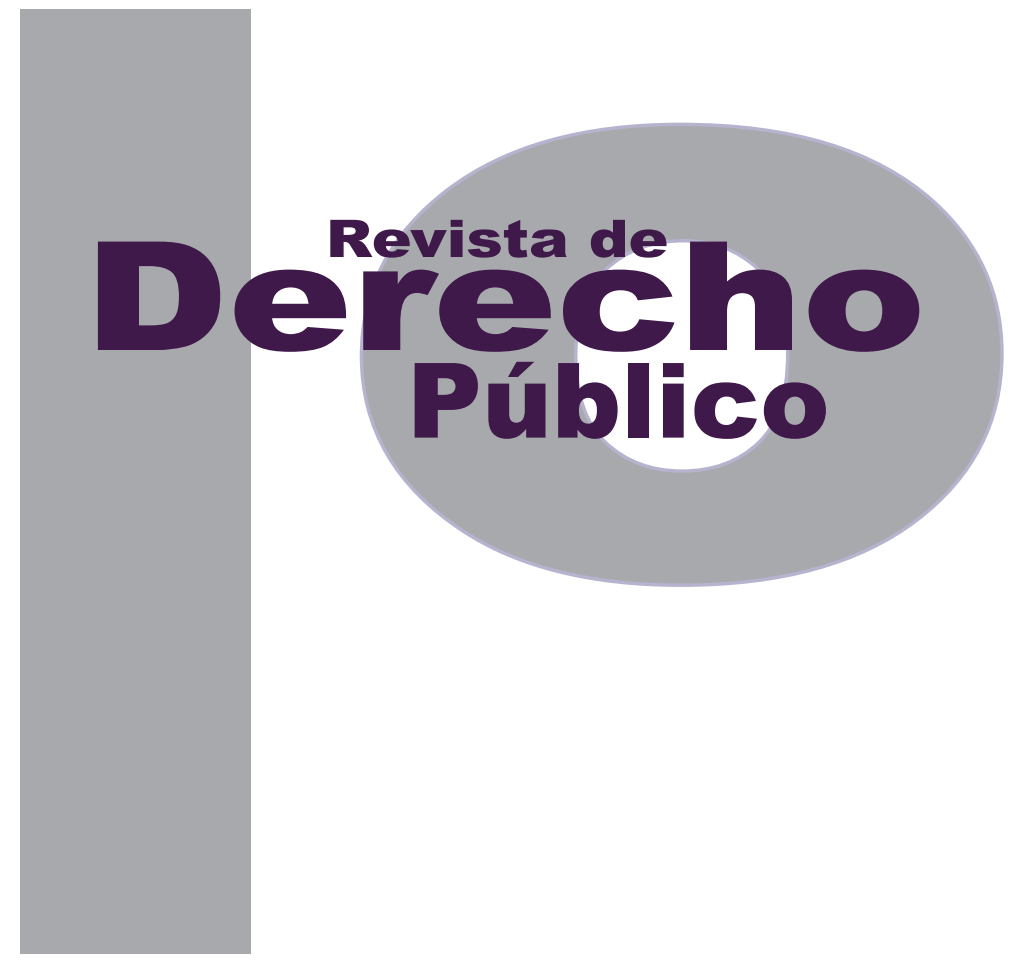

\title{
EVALUACIÓN EMPÍRICA DE LA TASACIÓN DE PERJUICIOS INMATERIALES EN COLOMBIA
}

\author{
Alejandro Peláez
}

Artículo de reflexión

DOI: http://dx.doi.org/10.15425/redepub.34.2015.27

Universidad de los Andes

Facultad de Derecho

Revista de Derecho Público N. ${ }^{\circ} 34$

Enero - Junio de 2015. ISSN 1909-7778 


\title{
Evaluación empírica de la tasación de perjuicios inmateriales en Colombia Resumen
}

En este artículo se realiza un ejercicio estadístico descriptivo para analizar la forma mediante la cual los jueces contencioso administrativos colombianos valoran los daños inmateriales en tres casos: lesiones, muerte y privación injusta de la libertad. En el análisis se encontró que los daños inmateriales, en el caso de lesión, aumentan de acuerdo con la gravedad de esta (equidad vertical) pero mantienen una variación alta en situaciones similares (inequidad horizontal); en los casos de privación injusta de la libertad la tasación es regresiva, es decir, a mayor tiempo de privación, menor indemnización en términos proporcionales. Al final se proponen recomendaciones para discutir la tasación de perjuicios por daños inmateriales desde un punto de vista práctico.

Palabras clave: responsabilidad del Estado, daño inmaterial, daño moral.

\section{An empirical analysis of the pain and suffering pricing methods in Colombian courts}

\begin{abstract}
In this article we quantitatively describe the way in which Colombian administrative judges quantify the pain and suffering awards in three types of cases: injuries, death and wrongful imprisonment. We found that pain and suffering awards in cases involving injuries are vertically fair, but that there is a lack of horizontal equity because of the high variation within a single category of injury. In cases of wrongful imprisonment, it was found that the pricing is regressive (the longer the deprivation, the lower the compensation in proportional terms). The article proposes new ways of pricing pain and suffering awards in Colombia.
\end{abstract}

Keywords: Pain and Suffering Damages.

\section{Avaliação empírica da taxação de prejuízos imateriais na Colômbia Resumo}

Neste artigo é realizado um exercício estatístico descritivo para analisar a forma mediante a qual os juízes contencioso administrativos colombianos valorizam os danos imaterializes em três casos: lesões, morte e privação injusta da liberdade. Na análise se encontrou que os danos imateriais, no caso de lesão, aumentam de acordo com a gravidade desta (equidade vertical) mas mantém uma variação alta em situações similares (inequidade horizontal); nos casos de privação injusta da liberdade a taxação é regressiva, ou seja, a maior tempo de privação, menor indenização em termos proporcionais. Ao final se propõem recomendações para discutir a taxação de prejuízos por danos imateriais desde um ponto de vista prático.

Palavras-chave: responsabilidade do Estado, dano imaterial, dano moral. 


\title{
Evaluación empírica de la tasación de perjuicios inmateriales en Colombia*
}

\author{
Alejandro Peláez ${ }^{* *}$
}

\section{SUMARIO}

Introducción - I. METODOLOGÍA - II. EL DESARROLLO DEL DAÑO INMATERIAL EN COLOMBIA - A. Tasación de perjuicios morales en caso de muerte, por parte del Consejo de Estado - B. Tasación de perjuicios morales en caso de lesiones personales - C. Tasación de perjuicios morales en caso de privación injusta de la libertad - D. Reglas de excepción - E. Test de proporcionalidad - F. Daños inmateriales por afectación relevante a bienes o derechos convencional y constitucionalmente amparados - G. El daño a la salud, fisiológico o biológico - III. DATOS ESTADÍSTICOS DESCRIPTIVOS - A. Familiares - B. Perjuicios inmateriales diferentes a los morales - C. Muerte - D. Lesiones - 1. Daño emocional - E. Privación injusta de la libertad - IV. CONCLUSIONES Y RECOMENDACIONES PRÁCTICAS - Referencias.

* $\quad$ Cómo citar este artículo: Peláez, A. (Junio, 2015). Evaluación empírica de la tasación de perjuicios inmateriales en Colombia. Revista de Derecho Público, 34. Universidad de los Andes (Colombia).

Las opiniones expresadas en este artículo son responsabilidad exclusiva del autor. Sin embargo, es importante señalar que el trabajo de recolección de datos fue realizado en conjunto con las siguientes personas vinculadas a la Agencia Nacional de Defensa Jurídica del Estado (ANDJE): Daniel González, Rodrigo Zuluaga, Cielo Martínez, Andrés Erazo y Yozira Daza. Un borrador de este artículo fue comentado por Diana Fajardo y Diego Márquez.

** Abogado de la Universidad de los Andes y funcionario de la Agencia Nacional de Defensa Jurídica del Estado. 
Introducción

En Colombia prolifera la literatura y la jurisprudencia sobre los principios filosóficos y doctrinales de los perjuicios inmateriales. ${ }^{1}$ Los debates son ricos en referencias a las tradiciones europeas, y se escribe a fondo sobre los fundamentos, la historia y la justificación ética y jurídica de este tipo de perjuicios. ${ }^{2}$ Pese a esto, hay muy poca discusión o información sobre los aspectos prácticos de estos perjuicios, en especial, respecto a los mecanismos o razonamientos que sirven como herramienta para tasar -en un caso concreto- los perjuicios inmateriales. Adicionalmente, la literatura colombiana no ha explorado empíricamente el comportamiento de los jueces cuando tasan este tipo de perjuicios, ni el impacto en la equidad que tienen esta cla-

1 Ejemplos de estas discusiones se encuentran en libros de texto como: El daño. Análisis comparativo de la responsabilidad extracontractual del Estado en el derecho colombiano y francés, escrito por Juan Carlos Henao (1998); el manual de Enrique Gil Botero, Temas de responsabilidad extracontractual del Estado (2001); el libro de Ricardo Hoyos Duque, La responsabilidad patrimonial de la administración pública (1984) o reflexiones en revistas académicas como "El daño moral, daño fisiológico y daño a la vida de relación en Colombia" de Felipe Navia Arroyo (2007), en la Revista de Derecho Privado de la Universidad Externado de Colombia. El tema también es relativamente popular en tesis de grado de diferentes facultades de Derecho, como es el caso de "Los perjuicios inmateriales en la responsabilidad extracontractual del Estado en Colombia" de Andrés Ricardo Mancipe para optar al título de abogado en la Universidad Javeriana (Mancipe, 2005). En varias sentencias del Consejo de Estado se ha reflexionado sobre la naturaleza de los daños inmateriales. Por ejemplo, en 1989 el consejero Gustavo de Greiff examinó a profundidad el tema en un caso de reconocimiento de perjuicios morales al hijo póstumo (sentencia de 16 de noviembre de 1989, expediente 5605), y el consejero Jesús María Carrillo se pronunció sobre el perjuicio estético a la luz de los perjuicios morales en una sentencia de la Sección Tercera del 25 de mayo de 2000 (expediente 12550).

2 La influencia de la doctrina y jurisprudencia francesa es patente en las obras de Juan Carlos Henao. Igualmente, algunos centros universitarios y editoriales nacionales han hecho esfuerzos por traducir y divulgar obras de tratadistas italianos que reflexionan sobre la naturaleza y características del daño inmaterial, en especial, aquel relacionado con el perjuicio estético. Ejemplos de estas traducciones son Scognamiglio (1962) y Rozo Sordini (2002). se de prácticas en las personas que utilizan el servicio de justicia, en particular, quienes han demandado por la privación injusta de la libertad. El fin de este ensayo es empezar a llenar estos vacíos.

Para desarrollar el argumento, se empieza por analizar empíricamente la forma en que los jueces colombianos tasan los perjuicios inmateriales de acuerdo con el caso que enfrentan, en particular, tratándose de lesiones físicas, muerte, privación injusta de la libertad y daños emocionales en los que los jueces tasaron y ordenaron perjuicios inmateriales. El ensayo se estructura de la siguiente manera: una primera sección donde se describen los datos utilizados y la metodología para su análisis; una segunda parte donde se resume la tradición judicial colombiana sobre los perjuicios inmateriales, con un especial énfasis en el trabajo de unificación de criterios para su reparación, contenido en el documento aprobado por el Consejo de Estado mediante Acta $n .^{\circ} 23$ de agosto de 2013; en el numeral III se describen los datos recolectados desglosados en cinco subsecciones: familiares de la víctima, daños inmateriales diferentes a morales, muerte, lesiones y privación injusta de la libertad. Por último, se presentan las conclusiones y recomendaciones prácticas que podrían adoptarse para regular la materia.

\section{METOdOLOGÍA}

Para el análisis se estudiaron cuatro muestras de expedientes de sentencias condenatorias contra la Nación obtenidas de las siguientes 
fuentes: juzgados administrativos y Tribunal Administrativo de Cundinamarca, Sección Tercera del Consejo de Estado para el periodo 2008-2013, censo de sentencias de la Sección Tercera del Consejo de Estado para 2013 y sentencias de la Corte Suprema de Justicia en el periodo 2008-2013. Las muestras están compuestas únicamente por expedientes con sentencia en contra de la Nación y tienen las siguientes características: la primera muestra corresponde a la totalidad de los expedientes de reparación directa recolectados en los archivos institucionales del Tribunal Administrativo de Cundinamarca y en los juzgados administrativos de Bogotá. La organización de dichos archivos no permite determinar el universo de los expedientes que en ellos reposan ni las características de estos, puesto que están almacenados en cajas dispuestas cronológicamente de acuerdo con el momento en que los expedientes Ilegan al archivo para ser guardados. No hay secciones claramente delimitadas para los expedientes fallados un año específico, por lo cual en un mismo estante pueden encontrarse expedientes con sentencias de diversos años, pero cercanos en el tiempo. Por lo tanto, el universo del que parte el estudio es el de las cajas que contienen expedientes archivados entre 2008 y 2013 , y que fueron fallados en este mismo periodo, aproximadamente.

Para el estudio se extrajo un universo de 2900 cajas del archivo del Tribunal Administrativo de Cundinamarca y de 7000 cajas del archivo central de los juzgados administrativos de Bogotá, con base en los cuales se calculó el tamaño de dos submuestras con un $95 \%$ de confianza y un $5 \%$ de error. En el archivo del Tribunal se debía recolectar la información de 340 cajas aleatoriamente seleccionadas de los estantes previamente establecidos; en el archivo central de los juzgados el número arrojado fue de 372 cajas. En ambos casos se decidió obtener una sobremuestra, ya que al desconocer el contenido de las cajas no se podía escoger ex-ante solo procesos de la jurisdicción contencioso administrativa en contra de entidades del orden nacional y, por ende, excluir expedientes de acciones de tutela y en contra de entidades territoriales. Igualmente, se excluyeron del análisis aquellos expedientes que terminaban antes del fallo por conciliación judicial, perención u otro motivo. Así, en el archivo del Tribunal se revisaron finalmente cerca de 700 cajas de las cuales se utilizó información de 351. En el archivo de juzgados se revisaron cerca de 500 cajas y se obtuvo información de 379. En ambos casos la muestra analizada estuvo por encima del número necesario para asegurar representatividad del universo.

La base final quedó compuesta por un total de 3468 expedientes, así: 2278 obtenidos en juzgados administrativos y 1190 en los tribunales. Estos expedientes fueron digitalizados y se usaron para responder a una serie de preguntas acerca de la duración de los procesos judiciales, la labor de los abogados, las causas de demanda y, sobre todo, el fallo de los jueces y magistrados. Los expedientes de los dos archivos (3408 en total) son representativos para el universo de los expedientes admitidos en juzgados de Bogotá o en el Tribunal de Cundinamarca, respectivamente, pero no son representativos del total 
de procesos de la jurisdicción administrativa fallados en Bogotá entre 2008 y 2013, puesto que se desconoce este conjunto y la proporción de estos que cursa en juzgados y en el Tribunal, por separado.

De esta muestra, 312 expedientes del Tribunal y 45 de los juzgados administrativos de Bogotá corresponden a casos de reparación directa. Después de seleccionar únicamente los expedientes con condenas contra la Nación, el tamaño de la muestra fue de 17 expedientes de juzgados y 72 expedientes del Tribunal Administrativo de Cundinamarca.

La segunda muestra fue obtenida de expedientes de la Sección Tercera del Consejo de Estado, años 2008-2013. En la primera selección se escogieron aleatoriamente 421 expedientes del universo total de sentencias publicadas por la Relatoría de dicho tribunal en el periodo señalado. Esta muestra tiene un $95 \%$ de confianza y un $5 \%$ de error. De esos 421, solo 93 expedientes contenían sentencias en las que la Nación era condenada, el resto correspondían a acciones diferentes a la reparación directa, procesos repetidos o procesos en donde no se condenaba a la Nación.

La tercera muestra estuvo conformada por la totalidad de las sentencias publicadas por la Relatoría del Consejo de Estado en el 2013. En esta, tenemos 267 sentencias con condenas en acciones de reparación directa. Dado que se analizaron todas las sentencias de 2013 , esta muestra es en realidad un censo sobre dicho periodo.
La cuarta muestra corresponde a una selección de sentencias de la Corte Suprema de Justicia en el periodo 2008-2013. Para ello, se le envió a dicho tribunal un oficio solicitando una copia de todas las sentencias de responsabilidad civil extracontractual (accidentes de tránsito, responsabilidad médica, etc.) en las que se condenara al pago de perjuicios morales. El resultado de esta pesquisa fue una selección de 15 sentencias que cumplían con los requisitos expresados.

Adicionalmente, para el análisis de la tasación de los perjuicios en casos de privación injusta de la libertad, se construyó una base de datos con la información de la totalidad de las sentencias en las que el Consejo de Estado condenó a la Nación por esta causa, desde 1996. Este trabajo constituye más un censo para ese tema concreto. Para el caso de perjuicios por heridos, se construyó una base de datos con sentencias condenatorias contra el Ministerio de Defensa, a partir de una selección aleatoria de 74 expedientes judiciales. Esta muestra, si bien es aleatoria, no es estadísticamente representativa.

\section{EL DESARROLLO DEL DAÑO INMATERIAL EN COLOMBIA ${ }^{3}$}

El daño moral ha sido definido como la afectación de los sentimientos íntimos de una persona, lo cual tiene su manifestación en la tristeza, la angustia, el temor, la desazón y la depresión a la que se ve expuesta la víctima como conse-

3 Catalina Franco colaboró en la redacción de esta sección. 
cuencia de un hecho dañoso imputable al Estado (Franco y Hernández, 2007).

El Consejo de Estado, para tasar los perjuicios inmateriales, ha construido lineamientos jurisprudenciales que incluyen topes, escalas y test de proporcionalidad. El 23 de agosto de 2014, la Sección Tercera del Consejo de Estado aprobó un documento en el que se recopila la línea jurisprudencial y se establecen los criterios unificados para la reparación de los perjuicios inmateriales.

Dicho documento está estructurado alrededor de los criterios de tasación de perjuicios morales para los siguientes casos: muerte, lesiones personales, privación injusta de la libertad y las reglas excepcionales aplicables a todos los casos de daños morales. Adicionalmente, el documento recoge los lineamientos para la tasación de los demás daños inmateriales, dentro de los cuales se encuentra el daño inmaterial por afectación de bienes o derechos convencional o constitucionalmente amparados y los daños a la salud.

\section{A. Tasación de perjuicios morales en caso de muerte, por parte del Consejo de Estado}

Para la tasación de los daños morales en caso de muerte, la Sección Tercera estableció diferentes topes de acuerdo con la cercanía afectiva de la víctima indirecta con la persona muerta y las pruebas sobre la afinidad presentadas por los demandantes.
Para determinar la cercanía efectiva con la persona muerta, la mencionada Sección desarrolló cinco niveles de relación basados en los grados de consanguinidad y afinidad definidos en el Código Civil. En la figura 1 se presenta un diagrama con los diferentes niveles de consanguinidad y las personas que lo componen.

Figura 1. Grados de consanguinidad y afinidad

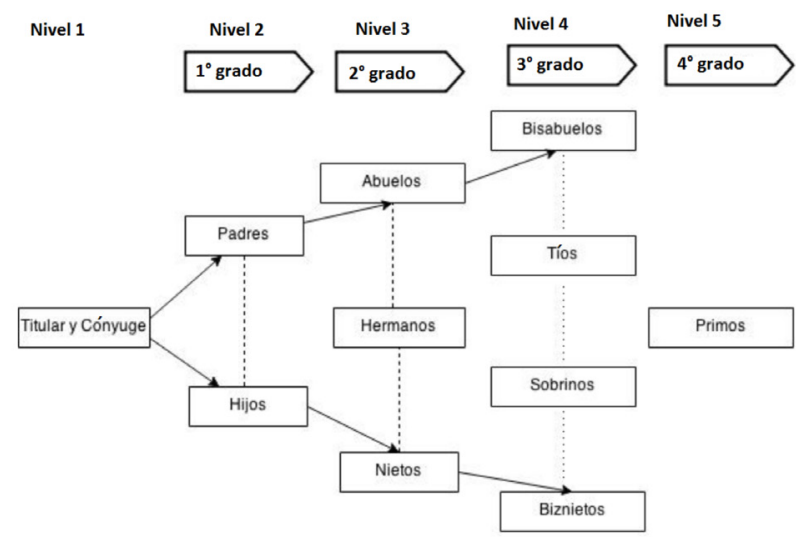

Fuente: elaboración propia.

El tope definido por la Sección Tercera para perjuicios morales a víctimas indirectas en el nivel 1 (parientes en primer grado de consanguinidad y los cónyuges o compañeros permanentes) es de 100 salarios mínimos mensuales legales vigentes (smmLv); en el nivel 2 (parientes en segundo grado de consanguinidad) de $50 \mathrm{smMLV}$ o el $50 \%$ del tope indemnizatorio; en el nivel 3 (parientes en tercer grado de consanguinidad o afinidad: bisabuelos, tíos, sobrinos, bisnietos y sus correspondientes cónyuges) de 35 smmLv; en el nivel 4 (víctimas indirectas que tienen un vínculo de consanguinidad o civil en cuarto grado: primos y sus cónyuges), de 25 smmLv; y por último, en el nivel 5 (víctimas indirectas con las cuales la persona fallecida no tenía relaciones familiares) de máximo 25 smmLv. 
Para los niveles 1 y 2, el demandante deberá aportar la prueba del estado civil. Para los niveles 3 y 4, se requerirá la prueba de la relación de consanguinidad o civil y prueba de la relación afectiva. Para el nivel 5 se deberá probar la relación afectiva.

\section{B. Tasación de perjuicios morales en caso de lesiones personales}

Para la tasación de los perjuicios morales en caso de lesiones personales, la Sección Tercera del Consejo de Estado ha construido unos criterios que tienen en cuenta dos variables: 1) la gravedad de la lesión y 2) el grado de afinidad de la víctima indirecta con el lesionado. En la tabla 1 se resumen los techos de acuerdo con la gravedad de la lesión sufrida (filas) y el tipo de víctima (columnas).

Tabla 1. Techo en SMMLV por daños inmateriales derivados de una lesión

\begin{tabular}{|c|c|c|c|c|c|}
\hline Gravedad de la lesión & Padres e hijos & $\begin{array}{c}\text { Hermanos, abuelos } \\
\text { y nietos }\end{array}$ & $\begin{array}{c}\text { Tíos, sobrinos, } \\
\text { bisabuelos }\end{array}$ & Primos & Amigos cercanos \\
\hline Mayor a $50 \%$ & 100 & 50 & 35 & 25 & 15 \\
\hline Entre $40 \%$ y $50 \%$ & 80 & 40 & 28 & 20 & 12 \\
\hline Entre $30 \%$ y $40 \%$ & 60 & 30 & 21 & 15 & 9 \\
\hline Entre $20 \%$ y $30 \%$ & 40 & 20 & 14 & 10 & 6 \\
\hline Entre $10 \%$ y $20 \%$ & 20 & 10 & 7 & 5 & 3 \\
\hline Entre $1 \%$ y $10 \%$ & 10 & 5 & 3.5 & 2.5 & 1.5 \\
\hline
\end{tabular}

Fuente: elaboración propia.

De acuerdo con el techo de la tabla 1, por ejemplo, el hermano de una víctima cuya lesión tuvo una gravedad correspondiente al 45\% no podrá recibir una indemnización por perjuicios morales superior a 40 smmLv, y un amigo de la víctima (con relación de afinidad probada en el proceso) no podrá recibir más de 12 smmLv en el mismo caso.

\section{Tasación de perjuicios morales en caso de privación injusta de la libertad}

La tasación de los perjuicios morales en casos en los que la víctima fue privada injustamente de la libertad se basa en la duración de dicha pena y la relación con la víctima cuando se trata de víctimas indirectas. En la tabla 2 se recogen los criterios de acuerdo con el término de la privación injusta (filas) y el grado de afinidad con la víctima cuando se trata de víctimas indirectas (la víctima directa se incluye en el nivel 1). 
Tabla 2. Techos en SMMLV por daños inmateriales en casode privación injusta de la libertad

\begin{tabular}{|c|c|c|c|c|c|}
\hline $\begin{array}{l}\text { Meses privado de la } \\
\text { libertad }\end{array}$ & Padres e hijos & $\begin{array}{l}\text { Hermanos, abuelos, } \\
\text { bisabuelos }\end{array}$ & $\begin{array}{l}\text { Tíos, sobrinos, } \\
\text { bisabuelos }\end{array}$ & Primos & Amigos cercanos \\
\hline$>18$ & 100 & 50 & 35 & 25 & 15 \\
\hline $12>18$ & 90 & 45 & 31.5 & 22.5 & 13.5 \\
\hline $9>12$ & 80 & 40 & 28 & 20 & 12 \\
\hline $9>6$ & 70 & 35 & 24.5 & 17.5 & \\
\hline $6>3$ & 50 & 25 & 17.5 & 12.5 & \\
\hline $3>1$ & 35 & 17.5 & 12.25 & 8.75 & \\
\hline$<1$ & 15 & 7.5 & 3.75 & 3.75 & \\
\hline
\end{tabular}

Fuente: elaboración propia.

\section{Reglas de excepción}

En casos excepcionales, como en graves violaciones a los derechos humanos, los jueces, de acuerdo con la jurisprudencia del Consejo de Estado, ${ }^{4}$ podrán otorgar una indemnización mayor a la señalada en los criterios anteriores. En este caso el juez, además de que tiene la carga de la argumentación, deberá sustentar las razones por las cuales supera los topes y guardar proporcionalidad con la intensidad del daño.

\section{E. Test de proporcionalidad}

En 2012, la Sección Tercera del Consejo de Estado discutió -y aprobó en una sentencia que ha sido marginal $-{ }^{5}$ la adopción de un test de proporcionalidad basado en tres elementos: la idoneidad, la necesidad y la proporcionalidad en sentido estricto.

4 Ver sentencias del $1^{\circ}$ de febrero de 2012, expedientes 21567 y 22199.

$5 \quad$ Ver sentencia de 18 de julio de 2012, expediente 22417.
En materia de idoneidad propuso que se determinara que la indemnización correspondiera a criterios de dolor, aflicción, pesar, apego, ansiedad, desasosiego, tristeza, respeto a la dignidad y valoración de las relaciones propias del núcleo familiar de la víctima, como convivencia, cercanía sentimental y apego.

Para la valoración de la necesidad planteó que se determinara la estructura de la relación familiar, lo que conllevaría a un mayor valor de reconocimiento económico en caso de muerte que en el de lesiones, así como a discernir más sobre la intensidad del perjuicio que sufre el núcleo familiar cercano frente a otros ámbitos familiares.

Sobre la proporcionalidad explicó que estaba constituido por la búsqueda de la compensación razonable y ponderada de los sufrimientos de la víctima sin la ruptura de los mandatos de prohibición de exceso y defecto.

Este test, que fue aprobado en una subsección de la Sección Tercera, no tuvo acogida en la Sec- 
ción Tercera del Consejo de Estado y su propuesta quedó limitada a un caso aislado y marginal.

\section{F. Daños inmateriales por afectación relevante a bienes o derechos convencional y constitucionalmente amparados}

En los casos de afectación de derechos, la Sección Tercera consideró relevante permitir la tasación de perjuicios, siempre y cuando su concreción se encuentre acreditada dentro del proceso.

Antes de la promulgación de la unificación de criterios y métodos para la tasación de perjuicios inmateriales realizada por la Sección Tercera, algunos magistrados habían fijado topes de 1000 smmlv por este tipo de daño, tal y como se puede observar en la siguiente cita tomada de la sentencia del Consejo de Estado del 25 de septiembre de 2013, expediente 36460:

Si el Estado colombiano reconoce legalmente la posibilidad de que los jueces decreten indemnizaciones del perjuicio inmaterial hasta la suma de 1.000 smmlv, en aquellas situaciones en las que el daño se deriva de una conducta punible, el juez de la reparación no puede ser indiferente a esas directrices objetivas que además vienen delimitadas por el derecho internacional de los derechos humanos y que se entronizan en el ordenamiento interno, concretamente a partir de la cláusula contenida en el artículo 93 de la Carta Política. En efecto, ya la jurisprudencia de la Corte Constitucional y de la Sala de Casación Penal de la Corte Suprema de Justicia han avalado la aplicación en concreto del artículo 97 del Código Penal, es decir, la posibilidad de que se decreten indemnizaciones por concepto de daño inmaterial hasta por 1.000 smmLv, conforme a la libre apreciación -según el arbitrio iuris y la sana crítica, que efectúe el operador judicial en cada caso concreto, siempre y cuando se encuentre acreditado que el daño es la consecuencia de la comisión de un delito, tal y como ocurre en el caso sub examine. Lo anterior, comoquiera que la Sala al examinar el contenido y alcance del artículo 97 del Código Penal vigente (ley 599 de 2000) -valoración del daño que en el Código Penal de 1980 se encontraba regulada en los artículos 103 y siguientes de ese cuerpo normativo encuentra que, en aquellos eventos en los cuales el daño antijurídico haya tenido origen en una conducta delictiva, como ocurre en el caso en estudio, siempre que ese daño resulte imputable al Estado la valoración del perjuicio extrapatrimonial podrá decretarse con fundamento en los baremos de la disposición mencionada, esto desde luego, dentro de los límites fijados en la litis, esto es, las pretensiones y excepciones contenidas en la demanda y la contestación; no obstante, se reitera, en aquellos supuestos en que el daño tenga origen en una grave violación a derechos humanos, los principios de congruencia y de no reformatio in pejus no operan en materia de la responsabilidad patrimonial del causante del daño y, por lo tanto, será posible que el juez desborde el marco contenido en la demanda y en la contestación, en lo atinente a la imposición de medidas de justicia restaurativa (...) cuando el daño antijurídico tiene su origen en la comisión de una conducta punible será aplicable el artículo 97 del c.P., bien que se trate o no de una grave lesión o vulneración de los derechos humanos, sólo que en estos últimos eventos el juez podrá exceder los límites fijados en la demanda, en lo que concierne a la imposición de medidas de justicia restaurativa. 
Esta posición fue matizada por la Sección Tercera, quien fijó un tope de 100 smmLv y determinó la necesidad de que -para este tipo de dañoslos jueces privilegien la compensación a través de medidas reparatorias no pecuniarias.

\section{G. El daño a la salud, fisiológico o biológico}

El daño a la salud es una categoría independiente de perjuicio inmaterial, la cual recoge los conceptos de la evolución jurisprudencial sobre perjuicio fisiológico, daño a la vida de relación y alteración grave de las condiciones de existencia. ${ }^{6}$

Este daño puede ser solicitado y decretado en los casos en que la afectación provenga de una lesión corporal que vulnere el derecho a la salud de una persona. De acuerdo con la definición jurisprudencial, el daño a la salud se reparará de la siguiente manera: i) una parte con base en el porcentaje de invalidez probado y, ii) otra parte será incrementada por el juez en una determinada proporción al primer valor, de conformidad con las consecuencias particulares y específicas de cada persona lesionada (Franco y Hernández, 2007).

Por regla general, y según los criterios fijados desde la sentencia de unificación del 14 de septiembre de 2011, expte. 19031 del Consejo de Estado, la indemnización por daño a la salud

6 Para profundizar en la evolución de este tipo de perjuicios, ver el artículo "Daño moral, daño fisiológico y daño a la vida de relación en Colombia" (Navia, 2007) o la sentencia del Consejo de Estado, Sala de lo Contencioso Administrativo, Sección Tercera, de 14 de septiembre de 2011, exptes. 19031 y 38222 (M. P.: Enrique Gil Botero). está sujeta a lo probado en el proceso, única y exclusivamente para la víctima directa, en una cuantía que no podrá superar los 100 smmıv de acuerdo con la gravedad de la lesión (ver tabla 4).

Tabla 4. Topes daño a la salud

\begin{tabular}{|l|r|}
\hline Gravedad de la lesión & $\begin{array}{l}\text { Techo indemnizatorio en } \\
\text { SMMLV }\end{array}$ \\
\hline$>50$ & 100 \\
\hline $50>40$ & 80 \\
\hline $40>30$ & 60 \\
\hline $30>20$ & 40 \\
\hline $20>10$ & 20 \\
\hline
\end{tabular}

Fuente: elaboración propia.

Para evaluar las consecuencias de la enfermedad o accidente, el juez debe considerar las siguientes variables:

1) La pérdida o anormalidad de una función psicológica, fisiológica o anatómica. 2) La anomalía, defecto o pérdida en un miembro, órgano, tejido u otra estructura corporal o mental. 3) La exteriorización de un estado patológico que refleje perturbaciones al nivel de un órgano. 4) La reversibilidad o irreversibilidad de la patología. 5) La restricción o ausencia de la capacidad para realizar una actividad normal o rutinaria. 6) Excesos en el desempeño y comportamiento dentro de una actividad normal o rutinaria. 7) Las limitaciones o impedimentos para el desempeño de un rol determinado. 8) Los factores sociales, culturales u ocupacionales. 9) La edad. 10) El sexo. 11) Las que tengan relación con la afectación de bienes placenteros, lúdicos y agradables de la víctima. 12) Las demás que se acrediten dentro del proceso (Ramírez vs. Hospital San Vicente de Paul, 2014). 
En casos excepcionales, el juez podrá otorgar una indemnización que supere el techo fijado, la cual no podrá superar en ningún caso el equivalente a 400 smmlv. Adicionalmente, los perjuicios por daño a un derecho y los perjuicios a la salud son excluyentes y no podrán realizarse pagos por ambos conceptos en un mismo caso.

\section{DATOS ESTADÍSTICOS DESCRIPTIVOS}

Las tres muestras ${ }^{7}$ fueron analizadas siguiendo un formulario en el que se incluía información sobre 76 variables para describir cada caso, ${ }^{8}$ agrupadas en tres grupos: en el primero se clasifica el caso de acuerdo con el tipo de juzgado donde se tomó la muestra (juzgado administrativo, Tribunal Administrativo de Cundinamarca, Consejo de Estado); ${ }^{9}$ en el segundo se califica el tipo de perjuicio sufrido por la víctima o los meses privados de la libertad cuando se trata de casos de privación injusta. Para calificar la gravedad de la lesión se utilizó la escala de nueve puntos empleada por la Asociación Nacional de Aseguradoras de Estados Unidos (NaIC por sus siglas en inglés). La escala tiene un rango que incluye desde los perjuicios emocionales hasta la muerte, pasando por varios puntos intermedios dependiendo de la gravedad del daño.

$7 \quad$ Este proceso se aplicó exclusivamente a las muestras de expedientes contencioso administrativos

8 El listado de las 76 variables se incluye como anexo del presente estudio.

9 Despachos con competencia en temas contencioso administrativos.
En la tabla 5 se presentan las frecuencias de casos por cada uno de los nueve niveles de lesión, empezando por las menos graves (emocionales) y terminando con los casos en los que la víctima murió. Como puede observarse en la tabla, cerca de la mitad de los procesos -independientemente del nivel del juzgado-, corresponden a casos en que la víctima murió como resultado de las lesiones sufridas.

Tabla 5. Frecuencias por tipo de daño

\begin{tabular}{|c|c|c|c|}
\hline & $\begin{array}{l}\text { Consejo de } \\
\text { Estado }\end{array}$ & Tribunal & Juzgados \\
\hline Daño emocional & 0.12 & 0.15 & 0.13 \\
\hline $\begin{array}{l}\text { lesión temporal- } \\
\text { Insignificante }\end{array}$ & 0.09 & 0.02 & 0.07 \\
\hline $\begin{array}{l}\text { lesión temporal- } \\
\text { menor }\end{array}$ & 0.05 & 0.02 & 0.07 \\
\hline $\begin{array}{l}\text { Lesión temporal- } \\
\text { Mayor }\end{array}$ & 0 & 0.04 & 0.13 \\
\hline $\begin{array}{l}\text { Lesión perman- } \\
\text { ente-menor }\end{array}$ & 0.06 & 0.17 & 0 \\
\hline $\begin{array}{l}\text { Lesión perman- } \\
\text { ente- significativa }\end{array}$ & 0.06 & 0.17 & 0 \\
\hline $\begin{array}{l}\text { Lesión perman- } \\
\text { ente-grave }\end{array}$ & 0 & 0.02 & 0 \\
\hline $\begin{array}{l}\text { Lesión perman- } \\
\text { ente-Mayor }\end{array}$ & 0.04 & 0.06 & 0.07 \\
\hline Muerte & 0.58 & 0.47 & 0.53 \\
\hline$n$ & 78 & 47 & 15 \\
\hline
\end{tabular}

Fuente: elaboración propia.

Adicionalmente, otros 41 casos (23\% del total de expedientes analizados) corresponden a reparaciones directas por privación injusta de la 
libertad, distribuidas así: 15 en la muestra del Consejo de Estado, 25 en la muestra del Tribunal Administrativo de Cundinamarca y 1 en los juzgados administrativos.

En la tercera categoría se agrupan las variables utilizadas, a saber: número de familiares de la víctima que solicitan perjuicios morales y el monto solicitado. Esta información incluye a los padres, cónyuges, hijos, hermanos, abuelos y otros parientes, y se encuentra discriminada en lo solicitado en la demanda y lo otorgado en primera y segunda instancia.

\section{A. Familiares de la víctima}

En la base de datos de sentencias contra el Ministerio de Defensa se recolectó información sobre el número de familiares y el monto otorgado en promedio a cada uno de ellos, como se aprecia en la tabla 6.

Tabla 6. Número y monto de indemnizaciones a familiares

\begin{tabular}{|l|r|r|r|r|}
\hline & $\begin{array}{c}\text { Número } \\
\text { de famili- } \\
\text { ares }\end{array}$ & $\begin{array}{c}\text { Total } \\
\text { víctima } \\
\text { indirecta } \\
\text { (familiar) }\end{array}$ & $\begin{array}{c}\text { Total } \\
\text { víctima } \\
\text { directa }\end{array}$ & $\begin{array}{c}\text { Total } \\
\text { fa- } \\
\text { milia }\end{array}$ \\
\hline Mínimo & 1 & 0 & 0 & 0 \\
\hline Mediana & 5 & 36.67 & 50 & 128 \\
\hline Media & 5,66 & 34.48 & 62.48 & 186 \\
\hline Máximo & 25 & 166.67 & 200 & 1000 \\
\hline
\end{tabular}

Fuente: elaboración propia.

En general, el tamaño de la familia tiene un efecto grande y estadísticamente significativo sobre la indemnización total que reciben los de- mandantes, tal y como puede verse en los resultados (ver tabla 6) de la regresión entre la variable dependiente, que recoge el monto total reconocido al grupo familiar, incluida la víctima, y la variable independiente, que corresponde al tamaño de la familia.

\section{Tabla 7. Regresión tamaño familiar}

\begin{tabular}{|c|c|}
\hline & Variable dependiente \\
\hline & Total reconocido \\
\hline \multirow{2}{*}{ Número familiares } & $40.379 * * *$ \\
\hline & $(4.476)$ \\
\hline \multirow{2}{*}{ Constante } & 41.044 \\
\hline & $(28.860)$ \\
\hline Observaciones & 97 \\
\hline $\mathrm{R}^{2}$ & 0.461 \\
\hline Rajustado $^{2}$ & 0.456 \\
\hline Error std & $141.801(d f=95)$ \\
\hline $\mathrm{F}$ & $81372 * * *(\mathrm{df}=1 ; 95)$ \\
\hline Nota & $*_{p}<0.1 ; * * p<0.05 ; * * * p<0.01$ \\
\hline
\end{tabular}

Fuente: elaboración propia.

De acuerdo con este resultado, por cada miembro adicional la indemnización global que debe pagar la Nación aumenta en 40.38 smmlv. Así, por ejemplo, la regresión permite suponer que la indemnización de una familia de tres personas llegaría a 162.18 smmLv y una de siete personas llegaría a 929.39 smmLv. Es claro, entonces, que el tamaño de la familia tiene un efecto importante en el monto que tiene que desembolsar el Estado cuando resulta condenado. 


\section{B. Perjuicios inmateriales diferentes} a los morales

En la base de datos de juzgados de Bogotá y el Tribunal de Cundinamarca hay $7.14 \%$ casos en las cuales los jueces otorgaron daños inmateriales diferentes a los morales ( $7.92 \%$ si se excluyen las conciliaciones). En la tabla 8 se detallan los estadísticos descriptivos para los daños concedidos en primera y segunda instancia, expresados en salarios mínimos, para la base de juzgados y tribunales en Bogotá y Cundinamarca, así como para la base de datos del Consejo de Estado en 2013 (32 casos).

Tabla 8. Número y tamaño de la indemnización a víctimasy familiares

\begin{tabular}{|c|c|c|c|c|}
\hline & $\begin{array}{l}\text { Numero de } \\
\text { familiares }\end{array}$ & $\begin{array}{l}\text { Total SM- } \\
\text { MLV víctima } \\
\text { indirecta } \\
\text { (familiar) }\end{array}$ & $\begin{array}{l}\text { Total } \\
\text { SMMLv } \\
\text { víctima } \\
\text { directa }\end{array}$ & $\begin{array}{l}\text { Total } \\
\text { SMMLV } \\
\text { familia }\end{array}$ \\
\hline Mínimo & 1 & 0 & 0 & 0 \\
\hline Mediana & 5 & 36.67 & 50 & 128 \\
\hline Media & 5.66 & 34.65 & 62.48 & 186 \\
\hline Máximo & 25 & 166.67 & 200 & 1000 \\
\hline
\end{tabular}

Fuente: elaboración propia.

La totalidad de estas indemnizaciones fueron concedidas en casos de lesión y, en su mayoría, corresponden al daño inmaterial llamado “daño a la vida de relación". Los montos son relativamente altos (casi iguales a los morales) si se comparan con lo que las víctimas reciben por perjuicios morales, en especial para los datos del Consejo de Estado. Por ejemplo, en los 32 casos de 2013 donde el Consejo de Estado otorgó perjuicios inmateriales diferentes a los morales, el mayor valor otorgado por estos últimos fue de 400 smmlv, mientras que el mayor valor en perjuicios morales fue de 230 smmLv. ${ }^{10}$ A diferencia del Consejo de Estado, en donde la participación de los perjuicios inmateriales diferentes a los morales es equivalente a cerca de la mitad de los perjuicios inmateriales otorgados (53\%), en la Sala Civil de la Corte Suprema de Justicia -en los pocos casos que fueron encontrados donde se otorgaron ambos tipos de perjuicios inmateriales- la participación de los perjuicios inmateriales diferentes a los morales es superior (76\%).

Adicionalmente, la correlación entre lo otorgado a la víctima por perjuicios morales y por perjuicios inmateriales en la primera instancia es alta (0.79) y en la segunda relativamente alta $(0.66)^{11}$ en ambos casos. En el caso de los datos del Consejo de Estado, la correlación no es estadísticamente significativa $(p=0.23)$. La correlación podría deberse a que los jueces - sin expresarlo explícitamente- están utilizando la valoración de los perjuicios morales como un patrón para tasar los demás perjuicios inmateriales otorgados. ${ }^{12}$

En los siguientes expedientes es posible observar cómo están cuantificando y argumentando los jueces, a partir de los casos en los que se

\footnotetext{
10 El promedio de perjuicios morales es de 75 y el de otros inmateriales es de 104. Sin embargo, la diferencia entre estos promedios no es estadísticamente significativa.

$11 p=0.0274$

12 Este punto sería interesante explorarlo con bases de datos más grandes que permitan verificar lo encontrado en las bases utilizadas.
} 
otorgan ambos o varios tipos de perjuicios inmateriales. En el caso García contra la Policía Nacional (2009), por ejemplo, el Consejo de Estado ordenó una indemnización de 80 salarios mínimos por perjuicios morales y 100 salarios mínimos por daño a la vida de relación, a un menor de edad que se hirió a sí mismo con un arma de dotación que había dejado desatendida un agente de policía. La argumentación para fijar el quantum de la indemnización es inexistente, tal y como se puede observar en la siguiente transcripción:

Por concepto de daño a la vida de relación o alteración a las condiciones de existencia (nueva denominación adoptada recientemente por la Sala para definir el primero) se mantendrá la decisión de conceder a Óscar García Villamil, la suma equivalente a 100 salarios mínimos legales mensuales vigentes, dada la gravedad sufrida por el afectado (García contra Policía Nacional, 2009).

El Tribunal Administrativo de Cundinamarca, en primera instancia, justificó así la cuantificación de estos perjuicios:

En el presente caso, aunque no está probado el daño a la vida en relación, la Sala procederá a tasarlo con base en las reglas de la experiencia, pues por las características del accidente, la incidencia del mismo en la vida de la menor y su corta edad, se presume que se ha afectado notablemente la vida y la mente del menor, pues no podrá realizar las actividades que venía realizando anteriormente, como los demás adolescentes (García contra Policía Nacional, 2009).
Es importante anotar que en la primera instancia, el Tribunal otorgó el mismo monto (100 SMmLv) para perjuicios morales y para el daño a la vida de relación, mientras que en el Consejo de Estado el magistrado ponente señaló que mantenía los valores reconocidos por el Tribunal y procedió a otorgarle 80 smmLv a la víctima por este concepto, lo cual corresponde a 20 smmLv menos que lo otorgado por el Tribunal en primera instancia.

Otro ejemplo de la aplicación de daños inmateriales diferentes a morales -en este caso, "alteración de las condiciones materiales de existencia"- lo encontramos en el caso Suárez contra la Policía Nacional (2011), en el que el Consejo de Estado otorgó 100 smmlv por perjuicios morales y otros 100 smmLv por alteración de las condiciones de existencia. En la sentencia de primera instancia, el Tribunal de Cundinamarca otorgó también el equivalente a 100 smmLv para ambos tipos de perjuicio. A diferencia del Consejo de Estado, el Tribunal denominó los otros perjuicios inmateriales como "perjuicio fisiológico".

El ejemplo más extremo ${ }^{13}$ de tasación de perjuicios inmateriales diferentes a morales, encontrado en la muestra de sentencias del Consejo de Estado del 2013, corresponde al caso Suárez contra el Instituto de Seguros Sociales (2013), relativo a una víctima a la que se le tuvo que practicar una histerectomía (extracción del aparato reproductor femenino) debido a una faIla médica. En esta ocasión, el Consejo de Es-

13 Por extremo se hace referencia al caso en que se otorgó el mayor monto por daños inmateriales diferentes a morales. 
tado le otorgó una indemnización de 400 sMmLv por concepto de daño a la salud y 100 por perjuicios morales. La argumentación para determinar esta suma está basada en un precedente de cinco sentencias del Consejo de Estado que inicia en 2007 y se funda en la gravedad de la lesión y la limitación a los derechos fundamentales de la víctima, tal y como se puede constatar en la siguiente cita:

En consecuencia, ésta Sub-Sección ordenará el reconocimiento por concepto de daño a la salud, de 400 salarios mínimos mensuales legales vigentes, de conformidad con el precedente jurisprudencial, teniendo en cuenta la gravedad de la lesión y los derechos fundamentales que le fueron limitados a la señora Mery Suárez Rueda con la misma (Suárez contra el Instituto de Seguros Sociales, 2013).

Como se puede observar, el juez no argumenta las razones por las cuales fijó la tasación de estos perjuicios en 400 smmLv y no en otro monto diferente. La inexistencia de argumentos dificulta entender por qué fijó esa suma y, en consecuencia, prever la tasación de este tipo de perjuicios en litigios futuros.

\section{Muerte}

La jurisprudencia nacional ha reconocido la discrecionalidad del juez para fijar el monto de los perjuicios morales. Sin embargo, dentro de los lineamientos que se han desarrollado, se adoptó un techo máximo de cien salarios mínimos mensuales como reconocimiento por el daño moral causado por la muerte de un pariente que pertenece al núcleo familiar (padre, hijo o cónyuge).
En los registros de pagos por concepto de perjuicios morales en casos de muerte de un miembro del núcleo familiar del demandante se encontró que, en promedio, los jueces contencioso administrativos los tasan en valores cercanos a los 100 smmLv (de 79 a 104 smmLv en promedio dependiendo de la muestra estudiada). Igualmente, se halló que en varios casos los jueces deciden ordenar perjuicios que superan el techo de 100 smmLv - en un caso duplican esa cifra-y en otros perjuicios muy por debajo del techo recomendado por la jurisprudencia. En la tabla 9 se presentan los estadísticos descriptivos para cada una de las tres bases, de acuerdo con el tipo de juzgado que realizó la valoración de los perjuicios morales.

Tabla 9. Valoración de perjuicios morales por muerte

\begin{tabular}{|l|r|r|r|r|r|}
\hline \multicolumn{7}{|c|}{ Tipos de base de datos } \\
\hline & & \multicolumn{2}{|c|}{$\begin{array}{c}\text { Despachos Cun- } \\
\text { dinamarca }\end{array}$} & \multicolumn{2}{c|}{ Consejo de Estado } \\
\cline { 2 - 7 } & $\begin{array}{c}\text { Milita- } \\
\text { res }\end{array}$ & $\begin{array}{c}\text { Juzgados } \\
\text { Btá }\end{array}$ & $\begin{array}{c}\text { Tribu- } \\
\text { nal }\end{array}$ & $\begin{array}{c}\text { Tribu- } \\
\text { nales }\end{array}$ & $\begin{array}{r}\text { Con- } \\
\text { sejo }\end{array}$ \\
\hline Máximo & 200 & 100 & 125 & 100 & 180 \\
\hline Mínimo & 50 & 100 & 50 & 30 & 30 \\
\hline Promedio & 103.62 & 100 & 88.08 & 78.67 & 93.09 \\
\hline $\begin{array}{l}\text { desvi- } \\
\text { ación } \\
\text { estándar }\end{array}$ & 28.75 & 0 & 24.46 & 27.1 & 25.23 \\
\hline Obs. & 38 & 8 & 22 & 18 & 35 \\
\hline
\end{tabular}

Fuente: elaboración propia.

Para profundizar en las diferencias que se encontraron en la tasación de perjuicios derivados de la muerte de un familiar cercano, se tomaron cuatro ejemplos que corresponden a dos casos en donde el juez tasó los perjuicios muy por debajo de lo recomendado tradicionalmente por la jurisprudencia y dos casos en los que lo hizo por encima de esta medida. 
En una sentencia de 2011, el Consejo de Estado (Morales contra Cajanal, 2011) tasó el perjuicio en 40 smmlv para cada uno de los padres de la víctima. El argumento para reducir el monto fue la concurrencia de culpas entre la víctima y la entidad pública, tal y como se puede observar en el siguiente aparte:

En consecuencia, aun cuando se configuró la culpa de la víctima, también está demostrado que la actuación del conductor del vehículo oficial tuvo incidencia en la producción del daño, de allí que, se tiene por acreditado que en el presente caso se configuró la denominada "culpa concurrente", que en realidad debe ser llamada "graduación de culpas", en razón a que, técnicamente, la incidencia en el daño se calcula conforme al grado de participación en la producción del mismo, por lo tanto, se confirmará la reducción en el porcentaje de la condena conforme lo señaló el tribunal de primera instancia (Morales contra Cajanal, 2011).

Otro caso donde el Consejo de Estado tasó los perjuicios morales para los padres de la víctima en 30 smmlv fue en Ballena contra Policía Nacional (2012). Al igual que en el caso anterior, la razón para reducir la indemnización fue la concurrencia de culpas:

Ahora bien, el acervo probatorio que obra en el expediente no deja a la Sala duda alguna en torno a que aunque en la producción del daño por el cual se demandó se vio involucrada la entidad demandada, también resulta cierto que en la producción de tal hecho dañoso tuvo participación directa la propia víctima. Así pues, se impone concluir que tal resultado dañoso resulta jurídicamente imputable tanto a la Administración como a la propia víctima.
Por lo expuesto, la Sala revocará la sentencia apelada, esto es la proferida por el Tribunal Administrativo de La Guajira el 13 de junio de 2002 y se declarará la responsabilidad de la entidad pública demandada pero reducirá el monto de la indemnización que debe asumir, en un 70 por ciento, en virtud de la participación directa que tuvo la víctima en el hecho dañoso y, en consecuencia, analizará el monto de los perjuicios solicitados en la demanda sobre la base de dicha disminución de la condena (Ballena contra Policía Nacional, 2012).

En contraste, en un caso de 2009 (Pinzón contra Empresa de Energía de Bogotá, 2009), el Consejo de Estado tasó los perjuicios morales por causa de muerte para un padre en 180 SMmLv. Como puede verse en el siguiente aparte, el Consejo primero reconoce que tradicionalmente la jurisprudencia ha fijado un techo de 100 smmLv para este tipo de casos y luego, sin mayores argumentos, procede a tasar el perjuicio en 180 smmLv.

Se solicitó en la demanda, una indemnización equivalente a $\mathbf{2} .000$ gramos de oro en favor de cada uno de los demandantes, esto es, de la madre, hermana y abuela de las víctimas. Se advierte, que para establecer el valor de la indemnización a reconocer a título de perjuicios morales, la Sala tendrá en cuenta los criterios establecidos en la sentencia de 6 de septiembre de 2001, expedientes Nos. 13.232 y 15.646, en la cual fijó tal indemnización en cien salarios mínimos legales mensuales vigentes el valor del perjuicio moral, en los eventos de mayor intensidad, abandonando así el criterio de aplicación extensiva de las normas que sobre la materia se habían adoptado en el Código Penal, por considerarlo improceden- 
te y para dar cumplimiento a lo previsto en los artículos 16 de la Ley 446 de 1998 y 178 del Código Contencioso Administrativo, que ordenan la reparación integral y equitativa del daño y la tasación de las condenas en moneda legal colombiana, respectivamente.

La Sala reconocerá la indemnización por perjuicios morales en favor de las demandantes, así: un valor equivalente a 180 salarios mínimos legales mensuales vigentes a favor de la madre de los fallecidos y de 90 smmLv a favor tanto de la hermana, como de la abuela materna de los mismos (Pinzón contra Empresa de Energía de Bogotá, 2009).

En un caso de muerte de dos hermanos menores de edad, causado por el estallido de una granada del Ejército Nacional, el Tribunal Administrativo de Cundinamarca tomó la decisión de superar el techo de 100 SmmLv fijado tradicionalmente por la jurisprudencia, y otorgar 125 sMmLV a cada uno de los padres de los dos hermanos muertos. La argumentación para superar el techo fue la siguiente:

Analizadas las circunstancias de modo en que fallecieron los menores, la edad que tenían para el momento del deceso, el impacto emocional que generó en sus familiares y la forma en que fueron hallados los cuerpos de las víctimas, verificado mediante registro fotográfico obrante en el presente proceso, la Sala deberá superar el criterio general de cuantificación del daño moral, bajo el criterio de la reparación integral y equitativa del daño, que exige el artículo 16 la ley 446 de 1998, en atención a que no existe patrón objetivo para medirlo dado su carácter inmaterial; por lo que la indemnización sólo cumple un papel de mitigación más que de resarcimiento o reposición (Barquero contra Ministerio de Defensa, 2009).

De la revisión empírica de los datos recolectados es posible obtener algunas reglas aplicables a la tasación de perjuicios en caso de muerte. En primer lugar, en la mayoría de los casos están concentrados alrededor de los 100 smmLv establecidos tradicionalmente por la jurisprudencia. En segundo lugar, los casos en los que los jueces tasan el perjuicio por debajo del estándar de 100 smmlv suelen corresponder a situaciones donde existió concurrencia de culpas entre la víctima y la entidad que causó el daño; en estos, los jueces reducen el monto de acuerdo con el grado de culpa - usualmente un porcentajeadjudicado a la víctima.

En los casos en los que los jueces conceden perjuicios por encima de los 100 smmLv las causas son más variadas. Por ejemplo, en aquellos donde hay varios muertos que tienen un familiar en común (dos hijos muertos de un mismo padre o dos padres de un hijo vivo), los jueces elevan la tasación por encima de los 100 smmLv. Esta evidencia es consistente con lo señalado en la revisión doctrinal y jurisprudencial reseñada en el acápite II: El desarrollo del daño inmaterial en Colombia, en particular, con el hecho de que la jurisprudencia ha permitido tasar perjuicios por encima del tope de 100 smmLv cuando se presenta una acumulación homogénea de perjuicios, lo cual ocurre cuando existen multiplicidad de causas que dan origen al daño moral. En otros casos, los jueces otorgan perjuicios por encima del techo sin mayor argumentación que sustente la tasación. 
En general, en los casos de muerte existe cierta homogeneidad en la forma en la que los jueces tasan los perjuicios morales, salvo los casos atípicos en donde superan el techo y no justifican la razón para hacerlo.

\section{Lesiones}

La tasación de los daños morales en caso de lesión es más compleja que en los casos de muerte. Con el fin de analizar la consistencia y equidad de las tasaciones realizadas por los jueces en las diferentes muestras se comparó el monto tasado con la gravedad de la lesión, de acuerdo con la escala de nueve puntos utilizada por la NAIc. La escala tiene un rango que incluye desde los perjuicios emocionales hasta la muerte, pasando por varios puntos intermedios dependiendo de la gravedad del daño, así:

1. Daño emocional únicamente.

2. Temporal insignificante (contusiones, cicatrices menores, raspones).

3. Temporal menor (infecciones, fracturas).

4. Temporal mayor (quemaduras).

5. Permanente menor (pérdida de dedos, pérdida o daño a órganos).

6. Permanente significativa (sordera, pérdida de miembros, pérdida de ojo, pérdida de pulmón o riñón).

7. Permanente mayor (paraplejia, ceguera, pérdida de dos miembros, daño cerebral).
8. Permanente grave (cuadriplejia, daño cerebral severo, prognosis fatal). ${ }^{14}$

9. Muerte.

La escala de la NAIC y otros sistemas médicos diseñados para medir la severidad de los perjuicios causados tienen una correlación fuerte con la mortalidad, morbilidad y tiempo de hospitalización posterior al trauma sufrido. La hipótesis aquí planteada es que la tasación de los perjuicios morales (el sufrimiento) debería también estar correlacionada con estas mediciones médicas sobre la gravedad de la lesión. La lógica detrás de esta hipótesis es simple: para intentar valorar de manera objetiva el dolor sufrido por una persona lesionada, quien tasa el dolor debe tener en cuenta la gravedad de la lesión como herramienta clave.

Para explorar la hipótesis se clasificó la gravedad de la lesión sufrida por la víctima en las diferentes muestras de acuerdo con la escala NAIC mencionada anteriormente. En todas, la variación de los perjuicios otorgados en cada una de las categorías es alta (en algunas va casi de 0 a 100 smmLv), pero el comportamiento general es diferente. En la del Consejo de Estado para el año 2013, como puede observarse en la figura 2 , no existe un patrón discernible entre los perjuicios otorgados en los diferentes niveles de la lesión, aunque es evidente una tendencia a aumentar la indemnización por perjuicios morales a medida que aumenta la gravedad de la lesión.

14 Los criterios señalados son tomados de la escala NAıc. Ver http://www. naic.org/ 
Figura 2. Número de salarios mínimos otorgados de acuerdo con la gravedad de la lesión

Salarios por tipo de perjuicio
$100-$

$80-$

$60^{-}$

$40-$

$20-$

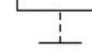

tenco-nsignticarse semp menor
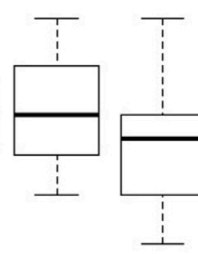
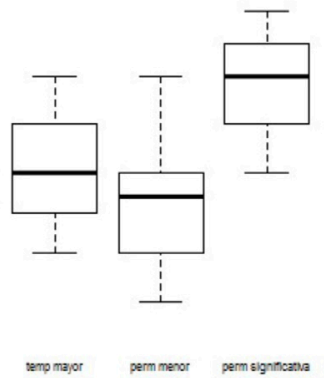

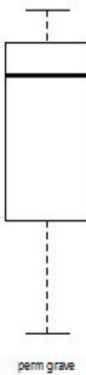

Fuente: elaboración propia con datos de sentencias del Consejo de Estado, año 2013.

En la gráfica realizada con los datos de daños causados por la fuerza pública o a miembros de la fuerza pública (figura 3) es más clara la relación entre los perjuicios inmateriales otorgados por los diferentes jueces y la gravedad de la lesión. ${ }^{15}$

Figura 3. Número de salarios mínimos otorgados de acuerdo con la gravedad de la lesión

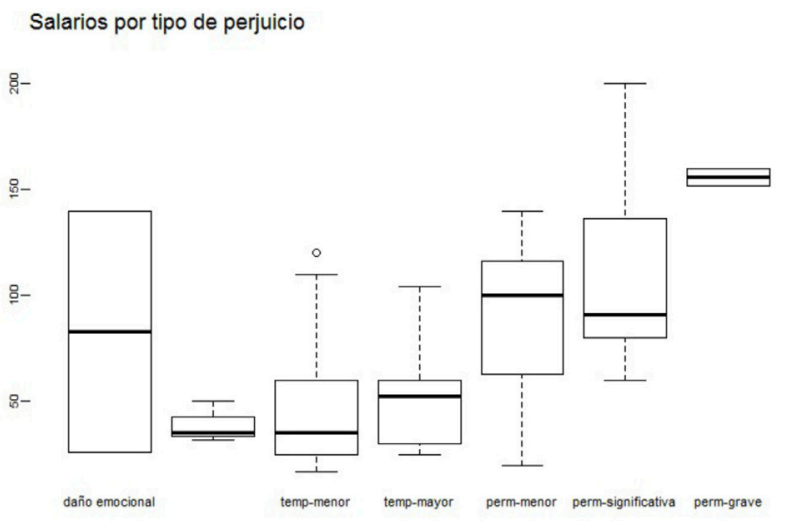

Fuente: elaboración propia con datos de sentencias del Consejo de Estado, año 2013.

15 La base de datos de la fuerza pública tiene un mayor número de observaciones y, por lo tanto, los resultados que se pueden obtener son más robustos. En la metodología se detallaron las especificaciones de las bases de datos utilizadas.
En general, existe una tendencia a que los jueces aumenten la tasación de perjuicios de manera acorde con la gravedad de la lesión sufrida. Esta concordancia puede denominarse equidad horizontal (correlación entre la gravedad de la lesión y el promedio de la indemnización). Sin embargo, se evidencia una alta variación en cada uno de los niveles de tipo de lesión y, por lo tanto, una gran inequidad vertical (daños similares tasados en montos diferentes).

Una parte de la variación en la tasación del perjuicio por lesión, al igual que en los casos de muerte, se debe a la concurrencia de culpas entre la víctima y la entidad, tal y como ocurrió en el caso Londoño contra las Empresas Públicas Municipales de Pereira (2008). En esa ocasión, el Consejo de Estado condenó a las Empresas Públicas de Pereira a pagar 50 smmlv por los perjuicios morales causados al señor Londoño, después de que quedara con una invalidez en la mitad de su cuerpo, producto de un accidente en su trabajo como obrero. En este caso, el Consejo consideró que el $50 \%$ de la culpa del accidente era atribuible al señor Londoño y por lo tanto tasó los perjuicios en 50 smmLv y no en 100, como habría ocurrido de no existir concurrencia de culpas:

Gregorio Londoño Soto -operario de la entidad demandada- se le habían suministrado los elementos de protección industrial, tales como cascos, guantes, caretas, etc., necesarios para adelantar su trabajo de una forma segura, así mismo, se le había hecho entrega del respectivo Reglamento de Higiene y Seguridad Industrial, donde se señalaba como deber de los trabajadores, el utilizar permanentemente 
los implementos de protección, sin embargo, el señor Londoño el día de los hechos, no usaba el casco plástico, por lo que al caer el ladrillo sobre su cabeza, sufrió las consecuencias ya descritas. Es decir, el señor Londoño se sometió irresponsablemente al riesgo que entraña la ejecución de una obra pública, al no usar los elementos de protección necesarios para la protección de su integridad personal (Londoño contra Empresas Públicas de Pereira, 2008).

En otros casos, las divergencias no se deben a la concurrencia de culpas sino a diferentes valoraciones del perjuicio causado. En la sentencia del caso Salamanca contra el Ministerio de Defensa (2009), por ejemplo, el Tribunal Contencioso Administrativo de Cundinamarca consideró que la menor de edad que sufrió un daño cerebral complejo (lesión permanente mayor en la escala de la NAIC), por causa de un accidente de tránsito con un vehículo del Ejército Nacional, debía ser indemnizada con 80 smmLv, mientras que en el caso Suárez contra la Policía Nacional (2000), el mismo tribunal consideró que la paraplejia causada a la señora Suárez por un accidente con arma de fuego debía ser compensada con 100 smmLv. De acuerdo con la escala de la NAIc, ambos perjuicios están en el mismo nivel. Igual ocurre en otros casos en los que, si bien la valoración de la NAIc es la misma, los jueces pueden considerar que el dolor y sufrimiento causado es diferente.

Avraham (2006) explica que existen algunas dos buenas razones que justifican la variación en una misma clase de perjuicio cuando se utiliza la escala de la NAIc. En primer lugar, en la misma escala de la NAıc pueden presentarse daños relativamente diferentes, por ejemplo, la sordera, la pérdida de un ojo o la pérdida de un riñón, todos clasificados en el nivel seis. El ejercicio de reducir los perjuicios a unas pocas categorías implica la necesidad de agrupar cosas que son distintas y, por lo tanto, se oscurecen diferencias que pueden ser claves. En consecuencia, los jueces pueden tasar perjuicios de manera disímil dentro de la misma categoría sin que esto implique un acto de inequidad o una valoración equivocada. En segundo lugar, la escala no considera la edad de la víctima y este dato puede ser importante al momento de valorar el dolor y el sufrimiento. Algunos jurados en Estados Unidos consideran que una persona joven que resulta con una incapacidad permanente sufrirá por más años que una persona de más edad y con menor expectativa de años de vida.

\section{Daño emocional}

En Colombia, a diferencia de otros países, existen algunos casos en los que personas que sufrieron daños a sus bienes reciben indemnizaciones por el dolor y sufrimiento que esto les causó, o por lesiones sin consecuencias físicas diferentes al temor psicológico sufrido por la víctima en un accidente. En promedio, en estos casos, los jueces otorgaron 42.78 smmLv por daños emocionales y los montos oscilaron entre los 25 SMMLV y 100 SMMLV. ${ }^{16}$

Para valorar estos perjuicios la jurisprudencia no ha construido criterios uniformes que permi-

16 Promedio de los casos en los que el juez concedió este tipo de daños inmateriales en las bases de datos construidas y analizadas por la NAIC. 
tan prever cuál será el monto tasado por el juez en cada caso concreto. Por ejemplo, en el caso Anaya contra el Ministerio de Defensa (2012), la víctima recibió una indemnización de 25 smmLv por perjuicios morales después de que su casa y local comercial fueran completamente destruidos en una incursión guerrillera. En el caso Navia contra el Ministerio de Transporte (2012), una familia demandó a la Nación por considerar que la construcción del viaducto Pereira-Dosquebradas aumentó la contaminación e inseguridad del sector y desvalorizó su vivienda. El caso fue fallado a favor de los demandantes y el Consejo de Estado ordenó una indemnización por los perjuicios morales causados a la familia. La argumentación para la tasación de estos perjuicios fue la siguiente:

Dado que se encuentra acreditado en el plenario que la señora Miriam Stella Navia López es la propietaria del inmueble afectado, en el que vivían su señora madre, Miriam López de Navia, y su hermano, Humberto Navia López, y que todos ellos resultaron afectados como consecuencia de la construcción del viaducto Pereira-Dosquebradas, la Sala condenará a la demandada a pagar la suma de 30 salarios mínimos mensuales legales vigentes para cada uno de ellos (Navia contra Ministerio de Transporte, 2012).

En el caso Narváez contra el Ministerio de Defensa, el Consejo de Estado ordenó una indemnización de 100 smmLv por perjuicios morales (y 50 por daño a la alteración grave de las condiciones de existencia) a una víctima que fue obligada a desplazarse de su domicilio por razones relacionadas con el conflicto armado.
En los tres casos mencionados los magistrados no exponen los argumentos o el método que utilizaron para tasar los perjuicios. Esta situación le impide al lector entender cuál fue su razonamiento al momento de definir los perjuicios morales cuando el daño causado no tiene un componente físico. ¿Por qué, por ejemplo, la persona cuya vivienda se afectó indirectamente por la construcción de un viaducto recibió una indemnización por perjuicios morales superior a la que recibió una familia cuya casa y local fueron completamente destruidos? Estos son algunos de los interrogantes que no pueden descifrarse.

\section{E. Privación injusta de la libertad}

La valoración de la indemnización por perjuicios morales en casos de privación injusta de la libertad es una muestra de cómo la jurisprudencia puede ser injusta, regresiva e inequitativa. En la gráfica 1 se marcaron todos los casos de privación injusta fallados por el Consejo de Estado en el periodo 2008-2013. El eje Y corresponde a la tasación de los perjuicios para cada caso y el eje $X$ al número de meses que estuvo privada de libertad la persona indemnizada. La gráfica, adicionalmente, distingue entre las personas privadas de la libertad en centro carcelario (puntos rojos), las privadas de la libertad en detención domiciliaria (puntos verdes) y un caso de libertad provisional (punto azul).

Las dos líneas que atraviesan por la mitad (roja y verde) muestran la tendencia de los datos; adicionalmente, se agrega una sombra mediante la aplicación de una técnica de suavizado 
denominada loess ${ }^{17}$ que permite visualizar la relación que tienen los datos. ${ }^{18} \mathrm{Al}$ observar las dos líneas se encuentra que ambas tienen la forma de una parábola que aumenta a medida que se acerca a los 50 meses y luego baja. En otras palabras, a medida que aumenta el tiempo de privación de libertad la indemnización termina por disminuir. El resultado de la aplicación del mecanismo de tasación utilizado por el Consejo de Estado termina creando una inequidad patente. Personas que están pocos meses privadas de la libertad reciben indemnizaciones mucho mayores, en términos relativos, que las que permanecieron privadas injustamente de la libertad por mayores periodos. Adicionalmente, la gráfica permite observar que hay varios casos en los que personas privadas de la libertad en su domicilio recibieron indemnizaciones superiores a las de aquellos que tuvieron que permanecer en un establecimiento de reclusión.

17 Para más información ver: Cleveland, Grosse y Shyu (1992).

18 "Nonparametric smoothers directly address the preceding problem. They can be used to locate a smooth curve among the data points without requiring any advance specification of the functional relationship between the variables. Instead, the fitting algorithm simply tries to follow the empirical concentration of the plotted points. The resultant fitted "line" should pass through the most dense areas of the data region in the scatterplot, regardless of the shape of the curve that is required in order to do so" (Jacoby, 2000, pp. 577-613).
Gráfica 1. Tendencias en la tasación del daño inmaterial en casos de privación injusta de la libertad

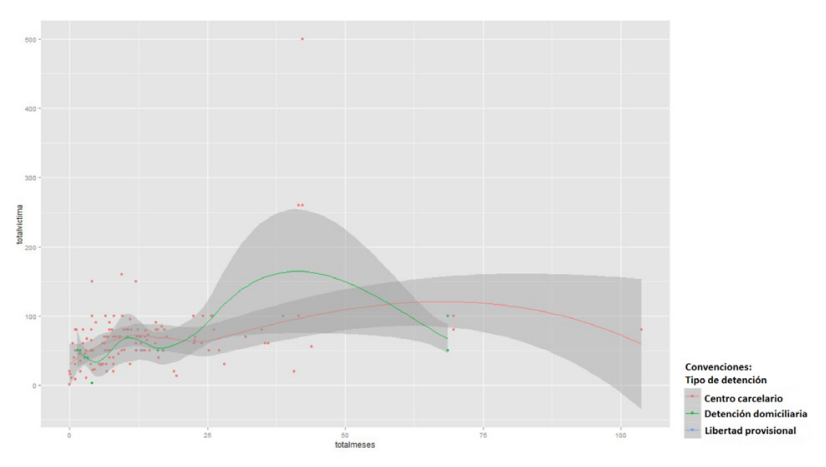

Fuente: elaboración propia.

Para ilustrar el punto es útil analizar algunos casos fallados por el Consejo de Estado que sí presentan los argumentos que sustentan la tasación de perjuicios en situaciones de privación de la libertad. En el caso Murgas contra la Rama Judicial (2013), el magistrado ponente explica el razonamiento para definir el monto que se le debe pagar a una víctima, así:

El juez administrativo tiene el arbitrio iudicis de determinar el monto a reconocer cuando se trata de perjuicios morales. Discrecionalidad que está regida: i) bajo el entendido de que la indemnización del perjuicio se hace a título de compensación, -pues "la suma establecida no se ajustará nunca al monto exacto del perjuicio, pero buscará, de alguna manera, restablecer el equilibrio roto con su ocurrencia"-, más no de restitución, ni de reparación; ii) por la aplicación del principio de equidad previsto en el artículo 16 de la Ley 446 de 1998; iii) por el deber de estar sustentada en los medios probatorios que obran en el proceso respecto del perjuicio y su intensidad, y por el iv) deber de estar fundamentada, cuando sea del caso, en otras providencias para efectos de garantizar el principio de igualdad. 
De acuerdo a la jurisprudencia de la Sala, se estimará un promedio de 5.1 salarios mínimos mensuales legales vigentes, por cada mes de privación injusta de la libertad, sin perjuicio de que se reconozca una cifra más alta según los factores que concurran en cada caso concreto.

Teniendo en cuenta que los señores Margladys y Carlos Araujo Murgas, permanecieron privados de la libertad durante 13 meses, y que dicha medida les produjo a ellos y a sus seres queridos angustia e incertidumbre, la Sala condenará a la Fiscalía General de la Nación a reconocer y pagar la correspondiente indemnización, así: A favor de Margladys Araujo Murgas y Carlos Araujo Murgas la suma equivalente a 60 S.M.L.M.V.

En este caso el razonamiento del magistrado es sencillo. Para tasar el perjuicio decidió estimarlo de acuerdo con el promedio otorgado por la Sala por cada mes de privación. Para el magistrado, la "jurisprudencia de la sala" se limita a tres sentencias citadas al pie de página con cuyos datos obtuvo el promedio de 5.1 salarios mínimos por cada mes que estuvo privada de la libertad injustamente la persona.

El razonamiento expuesto por el magistrado presenta cuatro problemas. El primero, que no es técnicamente adecuado seleccionar tres sentencias para realizar la operación matemática; si la idea era contar con una muestra que realmente representara el universo de sentencias en las cuales se tasaron los perjuicios por casos de privación injusta, ha debido obtener una muestra aleatoria que fuera estadísticamente significativa. El segundo, que es posible que utilizar el promedio como referente no sea adecua- do. El tercero, que omite la discusión sobre el uso de techos en la jurisprudencia del Consejo de Estado en lo que respecta a perjuicios morales, y no es claro si su propuesta elimina los topes o los mantiene implícitamente. Por último, el magistrado, después de señalar que la fórmula que se debe utilizar para tasar el perjuicio ha de ser el resultado de multiplicar el número de meses que estuvo la víctima privada de la libertad por 5.1 -que es el promedio obtenido-, se equivoca en la operación: 13 x 5.1 da 66 sMmLv y no 60 smmLv como aparece en el párrafo citado y en la parte resolutiva de la sentencia.

Para ilustrar estos puntos se puede hacer el ejercicio de manera técnica, siguiendo los argumentos principales del magistrado. En la tabla 10 se presentan los estadísticos descriptivos del pago por mes de privación de la libertad para la totalidad de las sentencias (95) en las que el Consejo de Estado condenó a la Nación por esta causa.

Tabla 10. Pagos por privación injusta de la libertad

\begin{tabular}{|l|l|l|l|r|}
\hline & $\begin{array}{l}\text { Número } \\
\text { de famili- } \\
\text { ares }\end{array}$ & $\begin{array}{l}\text { Total } \\
\text { SMMLv } \\
\text { víctima } \\
\text { indirecta } \\
\text { (familiar) }\end{array}$ & $\begin{array}{l}\text { Total } \\
\text { SMMLv } \\
\text { víctima } \\
\text { directa }\end{array}$ & $\begin{array}{l}\text { Total } \\
\text { SMMLv } \\
\text { familia }\end{array}$ \\
\hline Mínimo & 1 & 0 & 0 & 0 \\
\hline Mediana & 5 & 36.67 & 50 & 128 \\
\hline Mediana & 5.66 & 34.65 & 62.48 & 186 \\
\hline Máximo & 25 & 166.67 & 200 & 1000 \\
\hline
\end{tabular}

Fuente: elaboración propia.

Lo primero que se observa en la tabla es la gran dispersión de los datos. Hay casos que van des- 
de los 0 smmLv por cada mes que la víctima estuvo privada de la libertad hasta 900 smmLv por cada mes. ${ }^{19}$ Dado que hay casos con cifras muy altas, el promedio resultante es igualmente alto (24.31), sobre todo si se lo contrasta con el promedio obtenido por el magistrado en sus cálculos (5.1). Por esta razón, podría ser mejor utilizar una medida de centralidad de los datos que no sea tan sensible a los valores atípicos, como puede ser la mediana. Para estos datos, la mediana es 7.27 , que parece ser un monto más razonable para basar un criterio fundado en lo que tradicionalmente ha otorgado la jurisprudencia.

El criterio anotado por el Consejo de Estado tiene otro problema: no menciona si la metodología incluye o no un techo o tope para las indemnizaciones morales por esta causa. Si no existe un tope, usando los datos del Consejo de Estado habría casos en que las personas han debido recibir cerca de 500 smmLv por perjuicios morales, dado que estuvieron privadas de la libertad injustamente por casi 100 meses. En caso de que la metodología respetara el tradicional tope de 100 smmlv, todos los casos que superasen los 19 meses de privación injusta (el $25 \%$ los casos históricos fallados por esta causa en el Consejo de Estado desde 1996) recibirían indemnizaciones proporcionalmente menores, con lo cual se establecería un sistema de tasación inequitativo.

Unos meses después de esta providencia, la Sala Plena de la Sección Tercera del Consejo de

19 Sentencia del Consejo de Estado del 15/08/1996, radicado N10927 (M. P.: Daniel Suárez Hernández. En este caso, la persona estuvo un día privada de la libertad y recibió 50 SMmLv como indemnización por los perjuicios morales.
Estado unificó la jurisprudencia y fijó los siguientes criterios para la valoración de los perjuicios morales, en casos de personas privadas injustamente de la libertad:

Ahora bien, sin que de manera alguna implique un parámetro inmodificable que deba aplicarse en todos los casos, puesto que se insiste en la necesidad de que en cada proceso se valoren las circunstancias particulares que emergen del respectivo expediente, a manera de sugerencia y como parámetro que pueda orientar la decisión del juez en estos eventos, la Sala formula las siguientes reglas que sirven como guía en la tasación del perjuicio moral de la víctima directa en escenarios de privación injusta de la libertad: i) en los casos en que la privación sea superior a 18 meses, se reconozca la suma de 100 smmLv; ii) cuando supere los 12 meses y sea inferior a 18 meses, el monto de 90 smmlv; iii) si excedió los 9 meses y fue inferior a 12 meses, se sugiere el reconocimiento de 80 smmlv, iv) si fue mayor a 6 meses, pero no rebasó 9 meses hay lugar a fijar como indemnización la suma equivalente a 70 smmLv, v) de igual forma, en tanto la privación sea superior a 3 meses pero no sea mayor a 6 meses, el valor por concepto de este perjuicio correspondería a 50 smmlv, vi) si la medida supera 1 mes pero es inferior a 3 meses, se insinúa el reconocimiento de 35 smmlv, y vii) finalmente, si la detención no supera un mes, la reparación se podrá tasar en el equivalente a 15 smmLv, todo ello para la víctima directa - se insiste-y para cada uno de sus más cercanos o íntimos allegados.

Se reitera, los anteriores parámetros objetivos sirven como norte, guía o derrotero a efectos de que se garantice el principio de reparación integral del artículo 16 de la ley 446 de 1998, 
y los principios de igualdad material y dignidad humana, para lo cual el juez al momento de la valoración del daño moral es preciso que motive con suficiencia las circunstancias de tiempo, modo y lugar por las cuales se reconoce el respectivo perjuicio (Silva contra Fiscalía General de la Nación, 2013).

El nuevo método propuesto por el Consejo de Estado mantiene la estructura inequitativa de la propuesta anterior y el uso de escalones con valores para rangos de meses lo hace aún más inequitativo. Por ejemplo, una persona privada de la libertad un mes y medio recibe una indemnización de 35 smmlv, mientras que una que estuvo un mes recibe 15 smmLv. Adicionalmente, en términos relativos, la persona que estuvo una semana privada de la libertad recibe el equivalente a 2.14 salarios mínimos mensuales, mientras que la persona que estuvo 17 meses recibe solo 0.18 salarios por cada día privada de la libertad, es decir, 12 veces menos aun cuando tuvo que soportar una privación más larga en el establecimiento carcelario.

\section{CONCLUSIONES Y RECOMENDACIONES PRÁCTICAS}

Al analizar la información cuantitativa relacionada con la tasación de perjuicios inmateriales en las diferentes bases de datos que se utilizaron, se llegó a las siguientes conclusiones que son útiles desde un punto de vista práctico:

1. Existen algunos patrones en la tasación de perjuicios que parecen indicar un cierto grado de estructura en la forma en que los jueces ta- san los perjuicios inmateriales. En especial, parece existir una relación entre la gravedad de la lesión y la tasación de los perjuicios inmateriales, tanto morales como de otros tipos (vida de relación, salud, estéticos, etc.). Lo mismo ocurre en los casos de privación injusta de la libertad, aun cuando, como se explicó, los parámetros fijados por la jurisprudencia tienen efectos regresivos.

2. Existe mucha variación en la tasación de perjuicios que pueden considerarse similares. Esto puede ser indicio de incongruencias en los razonamientos utilizados para tasar los perjuicios o de diferencias difíciles de definir en cada caso. El problema es que los jueces tienden a no presentar con claridad los criterios que utilizaron para definir el monto a pagar por estos conceptos, lo cual le impide al lector saber si la diferencia entre la tasación de un caso a otro tiene un fundamento racional. Este fenómeno es patente en los casos de privación injusta de la libertad, en los que sería realmente sencillo utilizar un método medianamente objetivo y equitativo, y cualquier desviación debería tener una carga fuerte de argumentación por parte del juez que está tasando el perjuicio.

3. Desde un punto de vista fiscal, es claro que hay dos variables que tienen un impacto grande en el monto total asignado por cada caso: 1) el número de las víctimas indirectas - usualmente familiares- y 2) la proliferación de perjuicios inmateriales diferentes a los morales, sobre los que existe alguna jurisprudencia que tiende a elevar los techos muy por encima del monto tradicional de 100 smmLv. 
Como recomendaciones prácticas es posible pensar en la posibilidad de regular algunos aspectos de la tasación de perjuicios. En particular, se propone discutir sobre las siguientes medidas:

1. Englobar todos los perjuicios inmateriales en uno solo. A pesar de una prolífica literatura y jurisprudencia en donde se proponen nuevas categorías de perjuicios, y se discute la literatura internacional al tiempo que se realizan debates filosóficos, desde un punto de vista práctico sería mejor unificar estos perjuicios en una sola categoría con unas mismas reglas generales de tasación y aplicación. Esto evitaría la proliferación de casos en los que las víctimas reciben indemnizaciones con sumas muy diferentes, que dependen de la creatividad del abogado al momento de pedir perjuicios novedosos y de la liberalidad del juez a la hora de concederlos o tasarlos. Adicionalmente, unificar los criterios en una sola categoría permite predecir con mayor precisión las condenas y, por ende, facilita lograr acuerdos conciliatorios.

2. A pesar de las diferencias en las argumentaciones judiciales, existe relación entre la gravedad de la lesión y los perjuicios otorgados. En el documento de unificación de criterios para la tasación de perjuicios inmateriales presentado por la Sección Tercera, se avanzó mucho al utilizar un patrón de gravedad de la lesión para fijar los perjuicios morales en casos de lesiones. Sería útil profundizar en los detalles de este lineamiento y atar los perjuicios morales en casos de lesión a la pérdida de capacidad laboral, definida por los médicos de acuerdo con los baremos técnicos utilizados para este fin y no quedarse en la valoración subjetiva del juez sobre la gravedad de la lesión. En este punto sería importante elaborar una tabla de equivalencias entre los baremos civiles y los baremos militares que permitan utilizar el mismo patrón en ambos casos.

3. Los criterios jurisprudenciales utilizados para tasar los perjuicios morales en casos de privación injusta de la libertad deben cambiarse por un esquema más equitativo y acorde con la realidad penitenciaria nacional. Se propone una escala lineal mediante la cual se indemnice con $6.67 \%$ de un (1) SmmLv por cada día que la persona está privada de la libertad. La ventaja de este método es que no existiría un techo en la indemnización y, por ende, se eliminaría la inequidad con las personas que están privadas de la libertad por largos periodos (superiores a veinte meses). El razonamiento detrás de esta propuesta está basado en los datos obtenidos de la totalidad de las sentencias por privación injusta de la libertad que se muestran en la tabla 11.

Tabla 11. Escala de indemnización según meses de privación de la libertad

\begin{tabular}{|l|r|}
\hline & \multicolumn{2}{|l|}{ Meses privados de la libertad } \\
\hline Mínimo & 0 \\
\hline 1 cuartil & 3.05 \\
\hline Mediana & 8.90 \\
\hline Media & 14.59 \\
\hline 3 cuartil & 18.55 \\
\hline Máximo & 97 \\
\hline
\end{tabular}

Fuente: elaboración propia. 
Como puede verse, el $25 \%$ de los casos de privación de la libertad están por encima del techo fijado por el Consejo de Estado (18 meses). Como se explicó, el efecto de esta decisión es que todas estas personas reciben indemnizaciones inequitativas y convierten el sistema de tasación en un esquema estructuralmente injusto. Para resolver este punto, se toma el máximo valor (97 meses $)^{20}$ y se fija en este punto el techo, con una indemnización de 200 smmLv. Igualmente, se fija una escala lineal desde el día uno y un techo que crece al equivalente a $6.67 \%$ smmLv hasta llegar al tope de 200 smmLv en el mes 100.

El método para calcular el perjuicio sería simplemente la aplicación de la siguiente fórmula que se propone para discusión:

Indemnización $n_{i}=d * p$

Donde,

I = Indemnización total

d = días privado de la libertad

$p=6.67 \%$ de un salario mínimo mensual vigente

Como se ve en la tabla 12, la aplicación de la propuesta, utilizando los datos históricos, no solo habría evitado la inequidad, sino que habría reducido el costo fiscal a casi la mitad. Otra alternativa, con mayor impacto fiscal, sería fijar el techo en 100 salarios a los 100 meses. Con

20 Para facilitar los cálculos se redondea a 100 meses. esta propuesta, el costo pagado habría sido una cuarta parte de lo que se pagó por este concepto. Es importante anotar que con este método no se necesita fijar un techo, dado que los casos que superan los 100 meses de privación de la libertad son raros, y el impacto de otorgarle indemnizaciones superiores al techo sería fiscalmente marginal. Se recomienda utilizar este método para decidir -junto con otros criteriosel monto a ofrecer en conciliaciones.

Tabla 12. Simulación propuesta de valoración por privación injusta

\begin{tabular}{|l|r|r|}
\hline & \multicolumn{1}{|l|}{ Histórico } & Propuesta \\
\hline Meses (total) & 1382.2 & 1382.2 \\
\hline $\begin{array}{l}\text { Total perjuicios mo- } \\
\text { rales víctima (sMMLv) }\end{array}$ & 5746.59 & 2764 \\
\hline
\end{tabular}

Fuente: elaboración propia.

El daño moral por perjuicios que no tengan relación con un daño físico son un reto complejo y el documento de unificación de tasación de perjuicios inmateriales presentado por la Sección Tercera no menciona este tipo de casos. Al no existir un patrón (como la gravedad de la lesión) es difícil para cualquier operador definir en cuánto debe tasar el perjuicio. ¿Cuánto, por ejemplo, se le debe otorgar a una persona a la que una incursión guerrillera le destruye su hogar y se encuentra que el Estado es responsable por este daño?, ¿cuánto otorgar a la persona que, después de un accidente, solo sufre un daño emocional sin secuelas psicológicas? En casos en los que la cuantificación es compleja, debería exigírseles a los jueces una carga argumentativa fuerte y el respeto por el techo fijado para los perjuicios morales. 
Por último, un factor que impide racionalizar el gasto derivado de indemnizaciones judiciales es el tamaño de la familia y la posibilidad de que familiares hasta el tercer grado de consanguinidad, como son los sobrinos, bisabuelos, tíos o biznietos, puedan recibir indemnizaciones por perjuicios morales. Como se pudo observar, la indemnización del caso concreto depende principalmente del número de víctimas dependientes que presente el demandante. La sentencia de unificación de criterios para la tasación de perjuicios, al dejar explícita la posibilidad de que familiares lejanos puedan recibir indemnizaciones por perjuicios morales, abre la puerta para que en el futuro el número de las víctimas indirectas crezca exponencialmente. Para remediar esta situación, se propone fijar un techo de 150 SMmLv a la indemnización que puede recibir la familia, independientemente de su tamaño. La distribución de esta bolsa se realizaría siguiendo las pautas fijadas para la reparación administrativa de víctimas del conflicto, así:

50\% cónyuge o compañero (a) permanente, $50 \%$ hijos. A falta del cónyuge o compañero (a) permanente, $50 \%$ hijos y $50 \%$ padres. A falta de padres se repartirá entre los hijos. A falta de hijos, 50\% cónyuge o compañero (a) permanente, $50 \%$ padres. A falta de padres se entregará al cónyuge o compañero (a) permanente. A falta de los anteriores se entregará a los abuelos. De no contar con ninguno de los anteriores, la Nación realizará una indemnización simbólica y pública. En todo caso, de encontrarse relación con cónyuge y compañero (a) permanente vigente, la indemnización se repartirá entre estos por partes iguales. En tratándose de niños, ni- ñas o adolescentes (NNA), se constituirá encargo fiduciario (Ley 1448 de 2011).

\section{Referencias}

Anaya contra Ministerio de Defensa. Sentencia n. ${ }^{\circ}$ 66001-23-31-000-1998-0028401(22380) (Consejo de Estado, Sección Tercera, Subsección A, marzo 7 de 2012).

Avraham, R. (2006). Putting a Price on Pain and Suffering Damages: A Critique of the Current Aproaches and a Preliminary Proposal for Change. Northwestern University Law Review, 87-20.

Ballena contra Policía Nacional. Sentencia n. ${ }^{\circ}$ 44001-23-31-000-1999-00748-01(23306) (Consejo de Estado, Sección Tercera, Subsección A, marzo 21 de 2012).

Barquero contra Ministerio de Defensa. Sentencia n. ${ }^{\circ}$ 25000-232-6000-2005-0566 (Tribunal Administrativo de Cundinamarca, octubre 15 de 2009).

Cleveland, W., Grosse, E. y Shyu, W. (1992). Local regression models. En J. Chambers y $\mathrm{T}$. Hastie (eds.), Statistical Models in S. (págs. 309-373. New York: Chapman \& Hall.

Franco, C. y Hernández, A. (2007). Responsabilidad extracontractual del Estado. Análisis de la jurisprudencia del Consejo de Estado. Bogotá: Ediciones Nueva Jurídica. 
García contra Policía Nacional. Sentencia n. ${ }^{\circ}$ 25000-23-26-000-2002-0049-01 (31500) (Consejo de Estado, julio 8 de 2009).

Gil Botero, E. (2001). Temas de responsabilidad extracontractual del Estado. Bogotá: Librería Jurídica Sánchez R.

Henao, J. C. (1998). El daño: análisis comparativo de la responsabilidad extracontractual del Estado en derecho colombiano y francés. Bogotá: Universidad Externado de Colombia.

Hoyos Duque, R. (1984). La responsabilidad de la administración pública. Bogotá: Temis.

Jacoby, G. (2000). Loess: a noparametric, graphical tool for depicting relationships between variables. Electoral Studies, 577-613.

Londoño contra Empresas Públicas de Pereira. Sentencia n. ${ }^{\circ}$ 85001-23-31-000-199600283-01(15981) (Consejo de Estado, abril 24 de 2008).

Mancipe, A. R. (2005). Los perjuicios inmateriales en la responsabilidad extracontractual del Estado. (Tesis de grado). Pontificia Universidad Javeriana, Bogotá.

Morales contra Cajanal. Sentencia n. ${ }^{\circ} 17001-$ 23-31-000-1995-06021-01(19199) (Consejo de Estado, Sección Tercera, Subsección C, febrero 21 de 2011).

Murgas contra la Rama Judicial. Sentencia n. ${ }^{\circ}$ 20001-23-31-000-2001-00394-01(2749) (Consejo de Estado, mayo 31 de 2013).
Narváez contra Ministerio de Defensa. Sentencia n. $^{\circ} 2000123100019980371301$ (18.436) (Consejo de Estado, febrero 18 de 2012).

Navia contra Ministerio de Transporte. Sentencia n. ${ }^{\circ}$ 66001-23-31-000-1998-0028401(22380) (Consejo de Estado, marzo 7 de 2012).

Navia, J. F. (2007). Daño moral, daño fisiológico y daño en la vida de relación en Colombia. Revista de Derecho Privado, 289-305.

Pinzón contra Empresa de Energía de Bogotá. Sentencia n. ${ }^{\circ}$ 25000-23-26-000-199409783-01(17957) (Consejo de Estado, Sección Tercera, agosto 19 de 2009).

Ramírez contra Hospital San Vicente de Paul. Sentencia n. ${ }^{\circ}$ 23001-23-31-000-200100278-01(28804) (Consejo de Estado, agosto 28 de 2014).

Rozo Sordini, P. E. (2002). El daño biológico. Bogotá: Universidad Externado de Colombia.

Salamanca contra Ministerio de Defensa. Sentencia n. 200302044 (Tribunal Administrativo de Cundinamarca, julio 8 de 2009).

Scognamiglio, R. (1962). El daño moral: contribución a la teoría del daño extracontractual. Bogotá: Universidad Externado de Colombia.

Silva contra Fiscalía General de la Nación. Sentencia n. ${ }^{\circ}$ 05001-23-31-000-1996-00659- 
01(25022) (Consejo de Estado, agosto 28 de 2013).

Suárez contra ISS. Sentencia n. ${ }^{\circ}$ 25000-23-26000-1999-02632-01(25870) (Consejo de Estado, febrero 13 de 2013).
Suárez contra la Policía Nacional. Sentencia n. ${ }^{\circ}$ 199612596 (Tribunal Administrativo de Cundinamarca, octubre 5 de 2000). 